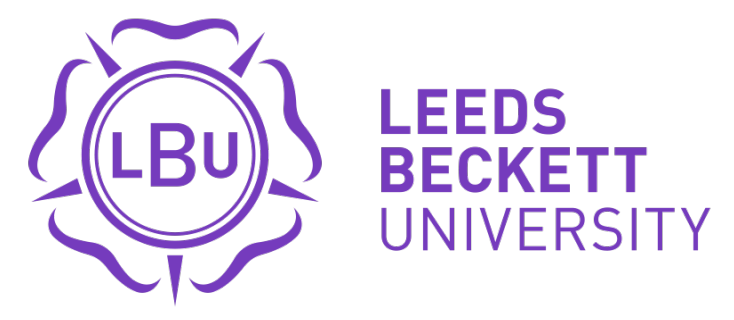

Citation:

Robert, $\mathrm{M}$ and Todisco, $\mathrm{T}$ and Stacey, $\mathrm{M}$ and Fujisawa, $\mathrm{T}$ and Allerhand, $\mathrm{M}$ and Woods, $\mathrm{D}$ and Reynolds, RM (2018) Risk of heat illness in men and women: a systematic review and meta-analysis. Environmental Research. ISSN 0013-9351 DOI: https://doi.org/10.1016/j.envres.2018.10.020

Link to Leeds Beckett Repository record:

https://eprints.leedsbeckett.ac.uk/id/eprint/5403/

Document Version:

Article (Accepted Version)

Creative Commons: Attribution-Noncommercial-No Derivative Works 4.0

The aim of the Leeds Beckett Repository is to provide open access to our research, as required by funder policies and permitted by publishers and copyright law.

The Leeds Beckett repository holds a wide range of publications, each of which has been checked for copyright and the relevant embargo period has been applied by the Research Services team.

We operate on a standard take-down policy. If you are the author or publisher of an output and you would like it removed from the repository, please contact us and we will investigate on a case-by-case basis.

Each thesis in the repository has been cleared where necessary by the author for third party copyright. If you would like a thesis to be removed from the repository or believe there is an issue with copyright, please contact us on openaccess@leedsbeckett.ac.uk and we will investigate on a case-by-case basis. 


\section{Risk of heat illness in men and women: a systematic review and meta-analysis}

Gifford Robert M MBChB, ${ }^{\mathrm{a}, \mathrm{b}}$ Todisco T MBBS, ${ }^{\mathrm{a}}$ Stacey M MD, ${ }^{\mathrm{b}}$ Fujisawa T PhD, ${ }^{\mathrm{a}}$ Allerhand M PhD, ${ }^{\mathrm{c}}$ Woods DR MD*, b,de,f Reynolds $\mathrm{RM} \mathrm{PhD}^{*} * * \mathrm{a}$

a. University/British Heart Foundation Centre for Cardiovascular Science, University of Edinburgh, Edinburgh, UK.

Email: r.reynolds@ed.ac.uk

Tel: + 441312426762

Fax: +44 1312426779

b. Defence Medical Services, Lichfield, UK

c. Centre for Statistics, School of Mathematics, University of Edinburgh, Edinburgh, UK

d. Research Institute for Sport, Physical Activity and Leisure, Leeds Beckett University, Leeds, UK

e. Northumbria and Newcastle NHS Trusts, Wansbeck General and Royal Victoria Infirmary, Newcastle, UK

f. University of Newcastle, Newcastle upon Tyne, UK

* Joint senior author

***Corresponding author

\section{Corresponding author}

Professor Rebecca Reynolds, University/British Heart Foundation Centre for Cardiovascular Science, Queen's Medical Research Institute, University of Edinburgh, Edinburgh, UK EH16 4TJ.

Email: r.reynolds@ed.ac.uk

Tel: + 441312426762

Fax: +44 1312426779 


\section{Abstract (PRISMA Style)}

\section{Background}

Heat illness (HI) is a growing global concern; its incidence has risen dramatically across the world in recent years. The individual factors whereby elevated core temperature produces HI are not well-understood. Given known physiological differences between men and women pertaining to temperature regulation, we hypothesized that women would be at increased risk of HI than men.

\section{Objectives}

We aimed to determine the relative risk of HI in women compared with men through an exhaustive literature review and meta-analysis.

\section{Methods}

We search PubMed and Ovid Medline databases from inception to Apr 2017. Search terms included all permutations of sex and heat illness (including heatstroke and exertional heat illness) with no language restrictions. We included adult or adolescent human data reporting comparable male and female $\mathrm{HI}$ rates. One reviewer identified and screened titles and abstracts. Two independent reviewers applied eligibility criteria. Disagreements were resolved with a third reviewer.

\section{Results}

Of 5888 articles identified by searches, 36 were included in the systematic review and 22 in the meta-analysis. The mean (standard deviation) quality score was 3.31(1.25)/5. Overall the rate among women was consistently lower than men across the lifespan. The male: female pooled IRR was 2.28 ( $\mathrm{p}<0.001,95 \%$ CI: 1.66-3.16). There was modest heterogeneity (between-studies variance $\left.\left(\tau^{2}\right)=0.02\right)$. The rates did not differ significantly when corrected for severity or occupation.

\section{Discussion}

The rate of HI was significantly increased in men compared with women. Risk for HI might be conferred by psychological and behavioral factors rather than physiological ones. Further research is required to delineate which groups are at greatest risk, leading to the development of mitigation strategies against HI.

\section{Other}

No funding was received. The authors acknowledge the support of the UK Women in Ground Close Combat Review. The Study was registered with PROSPREO CRD42017064739

\section{Keywords}

Heat illness, heatstroke, exertional heat illness, sex, male, female 
Funding sources, ethical approval.

No funding was received. The authors acknowledge the support of the UK Women in Ground Close Combat Review. As this was a systematic review, ethical approval was not required. 


\section{Introduction}

The term heat illness (HI) refers to incapacitating conditions directly related to a rise in body temperature, such as heatstroke (HS), as well as to milder disorders such as heat exhaustion, heat syncope, heat cramps and heat rash. Significant morbidity and fatal outcomes can result from HS and the broader spectrum of HI may present a significant healthcare burden to at risk populations. Heat-related illnesses generally peak on a seasonal basis and the annual burden has risen dramatically with the warming climate, in developed as well as developing countries.(Gu et al. 2016; Nelson et al. 2011; Tran et al. 2013) For example in Japan, the annual incidence of heatstroke in 2010 was 20-fold that in 1970,(Nakai et al. 1999) while in the United States (US), numerous studies have demonstrated a close association between extreme heat and HI-related mortality, making heat the leading weather-related cause of death.(Gubernot et al. 2015) (Gubernot et al. 2014) It is important to note that heat-related illnesses are only a small part of potential heat-related health impacts and epidemiological studies have linked heat exposure with numerous other causes of excess mortality, (Bai et al. ; Davis et al. 2003) and this is projected to increase with the warming climate.(Gasparrini et al.)

The development of HI relates to excessive heat stress, which may arise through increased metabolic heat production and/or reduced capacity to lose body heat to the external environment. Illness from heat stress relating specifically to physical exertion (Exertional Heat Illness, EHI) arises from increased heat production from active muscular contractions and may be precipitated by adverse climatic conditions (e.g. elevated ambient temperature and humidity) or encapsulating clothing ensembles worn in certain occupations and sports. Intrinsic factors leading individuals to develop HI, be it exertional or otherwise, are incompletely understood.(Leon and Bouchama 2015)No systematic review of the effect of female sex on risk of HI has been published, hence we therefore undertook an exhaustive review of extant literature, with a meta-analysis of published rates of $\mathrm{HI}$ by sex to determine any true difference in $\mathrm{HI}$ rate.

Evidence from prospective studies suggest women would be at increased risk of HI. Physical factors such as body mass index, body surface area and percent fat strongly influence body temperature responses to the heat and affect both sexes equally.(Notley et al.) However, cyclical changes in estrogen and progesterone specific to females are associated with thermoregulatory changes: core temperature is higher and there is a rightward shift in the 
temperature threshold for the onset of vasodilation in the luteal phase or in women using many hormonal contraceptives.(Wong and Hollowed 2017) Evaporative cooling at higher levels of heat stress is reduced in women than men(Gagnon and Kenny 2012) and cardiovascular fitness (which may be associated with protection against HI) is on average lower in women than men.(Bedno et al. 2014; Wallace et al. 2006) In pregnancy, heat dissipation and thermal stability appear enhanced, conferring fetal protection in the heat.(Lindqvist et al. ; Vaha-Eskeli et al.) Given the overall thrust of temperature physiology studies, which emphasize differences in thermoregulation caused by biological sex, our $a$ priori hypothesis was that women would be at greater risk of $\mathrm{HI}$ than men. Behavioral gender differences in physical activity in the heat would be expected to influence HI rates, for example where more physical activity is undertaken in the heat, or more preventive measures (such as active cooling) tend to be made by a particular gender and age. However this did not impact our hypothesis, since an exhaustive review would encompass a wide range of ages and normative sociocultural gender roles. Understanding the true sex difference might improve understanding of pathophysiological mechanisms or provide a basis for effective, targeted prevention strategies.

\section{Methods}

The systematic review was registered with PROSPERO international prospective register of systematic reviews (CRD42017064739) and reported according to MOOSE criteria for metaanalysis of observational studies.(Stroup et al. 2000)

All studies reporting unselected population-level cases or rates of $\mathrm{HI}$ in both men and women were included, where these were comparable: men and women were from the same population, exposed to the same meteorological conditions, and not explicitly or implicitly undertaking different levels of physical activity. We included cross-sectional, prospective and observational study designs, since these fulfilled these criteria. We included adult and adolescent data, using the Medline (OvidSP) and PubMed criteria of adult and adolescent (14 years or older), since children exhibit a different ability to thermoregulatory ability from adolescents or adults and sex differences pertaining to hormonal milieu would not be expected in pre-pubertal subjects.(Sinclair et al. ; Wong and Hollowed) Studies not reporting a source population, either stating the population size, or stating case rates (n per $N$ population per year; n/N/year), were excluded. Studies where cases were reported without a source population size or case rate, but where the male: female ratio of the source population 
could be deduced or reasonably assumed, were included in the systematic review but excluded from the meta-analysis. Studies not reporting HI by sex, studies aiming to report HI in the context of another medical condition or substance use, studies reporting all-cause mortality (not explicitly HI), case reports, case series and case-control studies were excluded.

We searched PubMed and Medline (OvidSP) on 3 April 2017 with no date limitation or language restriction. Our search was limited to humans aged over 14 years (the databases' cutoff for adolescent and adult). Our search strategy (available in supplemental table 1) aimed to identify articles reporting HI by sex based on an analysis of medical subject headings, terms, and key text words for all permutations of 'sex', 'gender' AND 'heat illness'. Bibliographies of pertinent articles were hand-searched. One investigator (RMG) reviewed all titles to exclude duplicates and no relevant literature. Two reviewers (RMG and TT) then independently judged eligibility of all abstracts. The selection and inclusion process is outlined in fig 1. Multiple reports on the same dataset were collated as one. Disagreements were resolved by referral to a third reviewer (RMR). Full-text copies of potentially relevant studies were sourced and independently assessed for compliance with the selection criteria. Articles in languages not spoken by the authorship were translated by colleagues at our institution (see acknowledgements).

\section{Data collection, quality and bias assessment}

Two investigators (RMG and TT) extracted data independently using a standardized form in Google Forms (Mountain View, California, USA). Extracted data included date and location of study, nature of exposure (e.g. heatwave event duration), male and female cases and population size and characteristics. Where data were alluded to in figures or narrative but were unquantified or incompletely reported, we contacted the authors of those studies up to three times. Fourteen authors were contacted, of whom eight responded with data. Studies reporting numbers of male and female cases, an estimate of background population size and a duration of exposure for $\mathrm{HI}$ incidents were included in the final meta-analysis. Where a study reported data from separate datasets and/or more than one outcome type, these were treated as distinct outcomes. A five-point quality and bias assessment scale was completed by the same investigators, awarding one point each for clarity of study objective, validity of diagnostic coding, study population characteristics (and any exclusion criteria likely to introduce bias), generalizability and clarity of statistical methods (supplemental table 2). Studies were scored as generalizable if they assessed HI in unselected populations, and were 
not deemed generalizable if they assessed niche populations, such as workers in some specific industry or sportspeople.

\section{Data synthesis}

A meta-analysis for incidence-rate ratio was completed using $\mathrm{R}$ package ( $\mathrm{R}$ Core Team (2017). R: A language and environment for statistical computing. R Foundation for Statistical Computing, Vienna, Austria.) "metafor" version 1.9-9, (W. Viechtbauer, http://www.metaforproject.org). A log incidence rate ratio (IRR) was calculated for each study, an effect size representing the ratio of male: female (M:F) incidence rates. Smaller effects indicate less difference between male and female incident rates. Confidence intervals were based on the sample estimate of the population variation; smaller samples were less precise and their confidence intervals were consequently wider. Weighting of each study's contribution was by its inverse variance, which depended on sample size. A random-effects model was then fitted to calculate the average effect size across studies, assuming heterogeneity. Clinical heterogeneity was tested using $\tau^{2}, I 2$ Cochrane's Q statistic. Two sub-analyses were performed: 1) according to four severity outcome types (1 - HI causing death, 2 - heat stroke or hospitalization, 3 - other HI or emergency department (ED) visit without hospitalization, 4 - mild HI), and 2) according to whether HI was occupational or non-occupational, where this information was available. Heterogeneity due to severity of outcome was assessed using an omnibus test comparing pairwise regression for severity types 2,3 , and 4 against type 1 , (the referent).(Viechtbauer 2007) Age-adjusted data were requested from authors, collated and presented in a single format but were not aggregated (due to variation in outcomes and source populations).

\section{Results}

Systematic review. The searches identified 5,888 results (Figure 1). Of these, 277 were considered potentially relevant based on title screening and proceeded to abstract review. A total of 172 full text articles were assessed for eligibility. Thirty-six studies were included, including one article identified from bibliographies.(Harduar Morano et al. 2015) Individual outcome data are presented for HI (table 1) and mortality (table 2). Definitions used are listed in Supplemental table 3. Data from three studies were collated since these reported the same dataset.(Nakai et al. 1999; Nakai 2012, 2015) Thirty-one nonfatal HI outcomes reported in 22 studies demonstrated higher rates of $\mathrm{HI}$ in men than women, (Armed Forces Health Surveillance Center 2011, 2012, 2013, 2014, 2015, 2016, 2017; Bai et al. 2014; Fortune et al. 
2013; Gu et al. 2016; Harduar Morano et al. 2016; Hess et al. 2014; Huffman et al. 2008; Hughson et al. 1980; Miyake 2012; Na et al. 2013; Pillai et al. 2014; Piver et al. 1999; Sanchez et al. 2010; Toloo et al. 2014; Wheeler et al. 2013; Yamamoto et al. 2015), of which eight applied to specialist populations (seven from the military and two from sports). Nine nonfatal HI outcomes reported in nine studies demonstrated higher rates in women than men (Armed Forces Health Surveillance Center 2011, 2012, 2013, 2014, 2015, 2016, 2017; Carter et al. 2005; Ellis et al. 1980) eight of which applied to specialist military populations. Higher mortality rates in men than women were demonstrated universally (16 outcomes from 15 studies, all reporting general population data).(Adcock et al. 2000; Centers for Disease and Prevention 2006; Ellis ; Fowler et al. 2013; Gu et al. 2016; Harduar Morano et al. 2016; Herbst et al. 2014; Hess et al. 2014; Mirabelli and Richardson 2005; Nashold et al. 1996; Taylor and McGwin 2000; Wheeler et al. 2013) Age-adjusted data (available in eight articles) graphically demonstrate the same pattern across the lifespan with higher rates among men than women, except where this pattern was reversed in patients aged over 80 in four studies (50\%) (figure 2).(Nakai et al. 1999; Nakai 2012, 2015; Pillai et al. 2014)

Meta-analysis. Twenty-two articles were included in the meta-analysis. The overall M:F IRR was 2.24 ( $\mathrm{p}<.001,95 \%$ CI: 1.62, 3.10, figure 3a). The IRR according to severity of HI was: mild HRI 1.88 (95\% CI 1.06, 2.22), moderate HI presented to ED but discharged 1.88 (95\% CI 1.24, 2.85), HI admitted to hospital 3.08 (95\% CI 1.44, 6.51), and HI-related mortality 1.89 (95\% CI 1.22-2.92). The M:F IRR of studies reporting occupational HI ( $n=3)$ was 5.66 (95\% CI 2.53, 12.64). In studies reporting non-occupational HI ( $\mathrm{n}=2)$ the M:F IRR was 2.96 $(95 \%$ CI 2.14, 4.10) (figure 3b). There was modest heterogeneity (between-studies variance $\left.\left(\tau^{2}\right)=0.02\right)$. The percentage of between-studies variance due to heterogeneity $\left(\mathrm{I}^{2}\right)$ was $98 \%$; Cochrane's "Q" statistic $\mathrm{Q}(\mathrm{df}=37)=2404,(\mathrm{p}<.001)$. There was no significant difference in $\mathrm{HI}$ severity; $\mathrm{QM}(\mathrm{df}=3)=1.1180, \mathrm{p}=0.77$.

Quality and bias assessment. The mean (SD) quality and bias score was 3.31(1.25) of a possible 5 (see Data collection, quality and bias assessment) (supplemental table 2). Twentynine $(80.5 \%)$ stated a study objective, $23(63.9 \%)$ used validated clinical diagnostic codes, 22 $(61.1 \%)$ had appropriate population characteristics (no exclusions were made which would introduce bias), 21 (58.3\%) were widely generalizable and 21 (58.3\%) stated statistical methods clearly. 


\section{Discussion}

In our systematic review, higher rates of HI in men than women were evidenced by 27 of 29 outcomes reported from 36 studies. All 13 studies reporting HI-related mortality found higher rates in men than women. The meta-analysis of 22 studies found a M:F IRR of 2.24 (95\% CI $1.62-3.10)$. The age-stratified difference in HI events and mortality, where reported, was greatest at a younger age (Fig $2 \mathrm{a}$ and $2 \mathrm{~b}$ ) but a greater reported number of events in men largely persisted across the lifespan. Based on a consensus assessment of bias and generalizability, there was moderate quality evidence to a meaningfully increased M:F IRR of HI.

Our findings are consistent with the earliest population studies of HI. Shattuck and Hilferty observed the HI mortality rate in the USA among men aged 30-70 was threefold that in women, 85 years ago.(1933) Since then, with increasing reporting of heat events, studies have reported greater all-cause mortality rates in women than men or no significant difference between sexes.(Fortune et al. 2013) Such differences have appropriately been attributed to longevity in women and hence a greater representation of older women with chronic diseases than men contributing to these rates. Our approach excluded studies reporting excess all-cause mortality and consequently data from some heat events, e.g. the 2003 heatwave affecting Europe and elsewhere, is not reported.(Huang et al. 2010; Michelozzi et al. 2005; Shen et al. 1998; Toulemon and Barbieri 2008) We focused on HI specifically due to known physiological sex differences related to temperature. In formulating our hypothesis (that the IRR would favor more HI in women than men), we did not assume that gender-associated differences in occupational heat stress would be consistent across countries (e.g. greater heat stress among men) or would apply to extremes of age. Those typically most at risk of HI are the young and very old, hence we hypothesized a predominance of female cases in these age categories would reflect an increased IRR among women overall. Our hypothesis was rejected, even after accounting for occupational HI and age, where possible.

This is the first published systematic review and meta-analysis examining the impact of sex on rates of HI. This study is relevant and timely; global temperatures and rates of HI are rising, $\{$ Gasparrini $\}$ yet risk factors for the occurrence of HI are poorly understood. Both our systematic review and meta-analysis encompassed a broad range of datasets, including from 
specific populations in the US military and sports events, occupational registries, hospitals, and local, regional and national population data. There were insufficient data to undertake meta-analyses for each type of dataset. Military studies demonstrated more mild HI or dehydration among women but more severe HI among men. Sports studies found HI and dehydration were both commoner among men. Similarly, regional hospital databases from Florida and medical examiner records from N Carolina, USA, both found work-related and non-work related ED visits and hospitalizations for HI were also commoner among men. While these observations might reflect greater physical exertion among men, more research is indicated to understand the reasons for this, since in the case of sports and military training, men and women could be expected to undergo similar levels of exertion.

Strengths of our study include hard endpoints (such as death and diagnostic coding, as opposed to self-reported symptoms) and quantitative analysis of data, mostly from large health databases, across several countries. Our wide inclusion criteria allowed assessment of the maximum number of $\mathrm{HI}$ cases to obtain a true IRR and was intended to reduce selection and confirmation bias. While different populations could theoretically be exposed to different sex-associated HI rates (e.g. occupational registries, military databases and hospital records), in order to be exhaustive, we did not exclude studies unless the heat stress exposure was stated to differ according to sex. We deliberately grouped HI outcomes crudely by severity (HI-related death, heatstroke/ hospital admission, presented to hospital but not admitted, mild HI). We could not categorize illness further by etiology (e.g. EHI or classical HS), because it these data were frequently unavailable in large datasets. Instead, we documented international classification of diseases (ICD) codes in the systematic review. We were also unable to account for repeat episodes in the same individual. Thus, while we could not reliably state whether studies were measuring precisely the same outcomes, within individual studies, identical outcomes were measured in men and women and both sexes would have been exposed to the same heat event. We excluded studies where the heat exposure to both men and women was unequal. Therefore, we are confident in the result of our meta-analysis, expressed as a ratio. We did not assess the absolute incidence of HI since this would vary greatly (e.g. by varying heat stress).

An unavoidable weakness of our study was that all datasets were formulated from diagnosis by clinicians and subsequent coding (ICD codes are listed in supplemental table 3). Identifying HI may be problematic since heat increases risk of deterioration in chronic 
diseases and associated mortality.(Gubernot et al. 2014) We excluded studies explicitly investigating the relationship between decompensated chronic illnesses (e.g. heart failure) and heat-related hospital admissions, as often it was not clear whether HI featured as a discrete diagnosis in the clinical episodes reported. The investigators of some of the studies included in our meta-analysis used broad outcomes which grouped HI with related diagnoses (e.g. heat-stress associated dehydration(Carter et al.) or sunburn(Mirabelli and Richardson 2005)) using death, admission or discharge as surrogate measures of severity. The ICD versions 9 and 10 delineates $\mathrm{HI}$ some of these related conditions, but nevertheless at the point of diagnosis or classification conflation of HI and other illness may have occurred. The ICD definition of HS changed in 1999 with the introduction of ICD10 clinical modification (CM), although in a longitudinal study examining deaths due to HI diagnoses from 1974 until 2015, ICD10-CM did not affect rate of HS diagnosis.(Nakai 2012)

A further limitation of this review is that we could not consider HS and EHI separately, as most studies did not quantify physical activity prior to the HI event and none compared activity in men and women. By nature, EHI is a difficult outcome to analyze, since rates of exertion vary greatly and diagnosis tends to be made by bystanders without the benefit of a secondary care medical facility. Greater activity in men could confound the observed M:F IRR. This is particularly pertinent to occupational HI. For example, Gubernot et al described a higher occupational heat-related mortality rate in men than women (RR 32.0 (95\% CI 17.060.0)) but did not describe the gender distribution of workers in different industries, for which RR of heat related deaths varied dramatically (the authors kindly provided us with further data but were unable to clarify HI rates by both employment type and sex).(2015) Were men to undergo greater average heat production through their occupation, this would be associated with a higher rate of HI. We have attempted to address this confounder by conducting a sub-analysis of 3 studies where incident-rate data are classified as nonoccupational (where a gender imbalance might be less likely) and/or occupational.(Fortune et al. 2013; Harduar Morano et al. 2016; Mirabelli and Richardson 2005) The M:F IRR was higher for occupational HI, of which a significant proportion would be expected to derive from physical exertion, but the same ratio did persist in non-occupational data. The investigators of other studies likely to represent a significant degree of EHI (especially those in athletes and the military) similarly were contacted and could not provide male and female data adjusted for activity.(Armed Forces Health Surveillance Center 2011, 2012, 2013, 2014, 2015, 2016, 2017; Carter et al. 2005; Huffman et al. 2008; Hughson et al. 1980) However, 
with increasing age the observed increased rates among men did persist. As age of presentation with HI increases, EHI might be less likely (either from occupation or recreation) and classical heatstroke more so.(Miyake 2013) When data were subdivided by age, we found the greater rate in men persisted across all ages. While differences in occupation would not be expected to affect gender differences in children or the elderly, men are more physically active than women in most countries across the lifespan.(Hallal et al. 2012)

\section{Unanswered questions and future research}

More prospective research is required to address specific causal factors for the observed sex differences in the development of HI. Only one prospective study was eligible for inclusion in the systematic review and none in the meta-analysis.(Hughson et al. 1980) While controlled prospective studies assessing development of HI are generally not ethically viable, there is a plethora of laboratory studies assessing thermal, sudomotor and cardiovascular response to heat in men and women, particularly during exercise. Several excellent reviews have been published summarizing sex-dependent aspects of such studies.(Charkoudian and Stachenfeld 2016; Gagnon and Kenny 2012; Kenny and Jay 2013; Kenny et al. 2016) Such studies do not explain our findings, since women have lower body surface area and cardiovascular fitness (Vogel and Friedl 1992) and a reduced sweating rate compared with men,(Gagnon et al. 2013; Nadel et al. 1974) which would increase propensity for HI.(Cramer and Jay 2016; Wallace et al. 2006) However such differences may be of diminished realworld relevance to HI risk.(Che Muhamed et al. 2016) Heat stroke is an inflammatory disorder occurring in the context of substantial elevation in core temperature and future research might prospectively examine sex dimorphism in HI pathophysiology rather than temperature per se, examining relevant novel markers such as copeptin (Leon and Bouchama 2015) $\{$ Stacey 2018\}

Estrogens appear to be protective against core temperature rise, an effect partially reversed by elevated progesterone levels in the midluteal phase.(Houghton et al. 2005; Stachenfeld et al. 2000) The effects of estrogen are reversed by inhibitors of nitric oxide synthase (NOS), indicating that the protective effect of estradiol is via upregulation of NOS.(Johnson and Kellogg 2010; Wong and Hollowed 2017) The clinical relevance of the effects of female sex hormones is not well understood and the effects of estrogens would not apply to postmenopausal patients. Prospective cohort studies using specialist populations could 
explore HI incidence according to sex, adjusted for other variables including BMI, body composition, and male sex hormone levels.

Behavioral gender differences have been less widely studied and are likely to be of greater importance to HI than physiological differences.(Marsh and Jenkins 2002) Women have demonstrated more circumspect behaviour and attitudes towards health effects of heat than men across the world,(Kenttamies and Karkola 2008; Khare et al. 2015; Li et al. 2016) which may be associated with reduced HI risk.(Liu et al. 2013) British women were shown to be more likely to undertake protective measures (for example, closing curtains during the day, opening windows at night, avoiding physical exertion or using fans or air conditioners) than men in the heat.(Khare et al. 2015) In a systematic review and meta-analysis of genderassociated risk perception, Byrnes et al show a consistently greater risk taking behaviour in men than women, especially in physical and intellectual tasks.(Byrnes et al. 1999)

Our findings have implications for public health policy, especially in hot climates. For example, in settings of high occupational heat stress, HI might be prevented in maledominant workforces through policies like regular break enforcement. Broader legislative changes protecting men in the heat may be considered by public health advisers, and fiscal considerations, such as the cost to certain sectors of the economy of greater HI among men, may be weighed against cost barriers of air conditioning or other domestic or workplace cooling options.(Lundgren-Kownacki et al.)While the data we have reported come from a wide range of countries, regulatory considerations ought to be proportionate to need (absolute $\mathrm{HI}$ rates) and the prevailing gender normative. It could be beneficial to measure the effectiveness of such interventions using database studies, comparing gender differences in HI before and after.

In the studies incorporated in our meta-analysis, it may be that a greater proportion of men than women were subject to heat stress arising from volitional activities (recreational, or selfpaced working) or non-volitional tasks (e.g. military exposures such as marching at grouppace in formation), in which gender-dependent factors such as risk perception and sociocultural normative behaviors operated to predispose greater male risk of HI.(Burkart et al. 2014; Stacey et al. 2015; Tawatsupa et al. 2013) Qualitative studies reveal important gender differences in perception of heat symptoms, with women more likely to report symptoms in a heat event than men.(Belanger et al. 2014; Nitschke et al. 2013) This may lead 
to later presentation among men and increase the likelihood of men experiencing more severe HI than women.(Armed Forces Health Surveillance Center 2011, 2012, 2013, 2014, 2015, 2016, 2017) As the gender employment gap closes and normative gender roles blur in many societies today, it may be that the differences observed in this review reduce in future. Further qualitative research is required to explore gender-associated differences in HI symptom perception and risk perception and their associations with hard endpoints such as heat-related mortality.(Boeckmann and Rohn 2014)

The studies included are population average outcomes, hence we have assessed association not causation. Our data cannot delineate if the factors outlined here or others, such as differences in behaviour, body mass index, hydration, nature intensity and duration of exercise, medication use, ambient temperature, humidity or clothing are responsible. However, our consistent observation from diverse populations reduces the likelihood of any one factor being culprit

We hypothesize our findings relate to a trans-cultural, perhaps even innate, gender normative. Factors that relate to differences in heat illness, including both physiological and behavioral factors (such as occupation), are likely to contribute to our finding. The implications are twofold. For researchers, prospective studies of well-matched men and women are required to understand causal risk factors for HI; ours is not the appropriate study design to assess the etiology of heat illness. For policymakers, the immediate implication of our findings is that a public health message could be indicated, targeting men. It is not clear if it is the tasks being undertaken in the heat, or the manner in which tasks are undertaken, which are responsible for the increased rate of HI. Trials of increased awareness and intervention strategies focused on men should be considered.

\section{Conclusion}

We found a reduced overall observed rate of $\mathrm{HI}$ in women compared to men at the population level. This applied to deaths, hospital admissions, hospital presentations and mild HI across the lifespan. This observation was consistent across four decades of data. The increased rate of $\mathrm{HI}$ and mortality in men may relate to a range of factors described here and further research is required to define these more clearly. A greater understanding of the factors increasing morbidity and mortality from $\mathrm{HI}$ is needed as global temperatures continue to climb. It may be that men might benefit from developing behavioral strategies which protect 
women from HI, such as earlier reporting of symptoms, protective behaviors and perception of the HI threat.

\section{Declaration of interest:}

None. 


\section{Acknowledgments}

We are grateful to authors who kindly responded to request for additional information:

Dr C Lansdowne-Bricker, Dr G Luber, Dr Y Miyake, Prof S Nakai, Prof C Mustard, Dr Edouard Pascal

Prof S Hajat, Prof T Timpka, Dr C Lansdowne-Bricker, Dr J Gindler, Dr D Gubernot Translators:

Miss L Yang

\section{Author Contribution}

RMG conducted the literature search, screening, eligibility and quality assessment, data extraction and drafted the manuscript.

TT also conducted the eligibility and quality assessment and data extraction

MS assisted in developing the systematic review and meta-analysis, provided expertise on the interpretation of results and contributed to drafting the manuscript

TF interpreted and extracted data from Japanese papers and corresponded with their authors. MA performed the meta-analysis

DRW and RMR jointly provided expertise and editorial oversight. RR was third (deciding) reviewer for disagreements in eligibility and quality assessment. 


\section{References}

Adcock MP, Bines WH., Smith FW. 2000. Heat-related illnesses, deaths, and risk factors--cincinnati and dayton, ohio, 1999, and united states, 1979-1997. (Reprinted) JAMA 284:34-35.

Armed Forces Health Surveillance Center. 2011. Update: Heat injuries, active component, u.S. Armed forces, 2010. MSMR 18:6-8. Armed Forces Health Surveillance Center. 2012. Update: Heat injuries, active component, u.S. Armed forces, 2011. MSMR 19:14-16. Armed Forces Health Surveillance Center. 2013. Update: Heat injuries, active component, u.S. Armed forces, 2012. MSMR 20:17-20. Armed Forces Health Surveillance Center. 2014. Update: Heat injuries, active component, u.S. Armed forces, 2013. MSMR 21:10-13. Armed Forces Health Surveillance Center. 2015. Update: Heat injuries, active component, u.S. Armed forces, 2014. MSMR 22:17-20. Armed Forces Health Surveillance Center. 2016. Update: Heat injuries, active component, u.S. Army, navy, air force, and marine corps, 2015. MSMR 23:16-19.

Armed Forces Health Surveillance Center. 2017. Update: Heat illness, active component, u.S. Armed forces, 2016. Msmr 24:9-13.

Bai L, Ding G, Gu S, Bi P, Su B, Qin D, et al. 2014. The effects of summer temperature and heat waves on heat-related illness in a coastal city of china, 2011-2013. Environmental Research 132:212-219.

Bedno SA, Urban N, Boivin MR, Cowan DN. 2014. Fitness, obesity and risk of heat illness among army trainees. Occupational Medicine (Oxford) 64:461-467.

Belanger D, Gosselin P, Valois P, Abdous B. 2014. Perceived adverse health effects of heat and their determinants in deprived neighbourhoods: A cross-sectional survey of nine cities in canada. Int J Environ Res Public Health 11:11028-11053. doi: 11010.13390/ijerph111111028.

Boeckmann M, Rohn I. 2014. Is planned adaptation to heat reducing heat-related mortality and illness? A systematic review. BMC public health 14:1112.

Burkart K, Breitner S, Schneider A, Khan MM, Kramer A, Endlicher W. 2014. An analysis of heat effects in different subpopulations of bangladesh. International Journal of Biometeorology 58:227-237.

Byrnes JP, Miller DC, Schafer WD. 1999. Gender differences in risk taking: A meta-analysis. Psychological bulletin 125:367-383.

Carter R, 3rd, Cheuvront SN, Williams JO, Kolka MA, Stephenson LA, Sawka MN, et al. 2005. Epidemiology of hospitalizations and deaths from heat illness in soldiers. Medicine \& Science in Sports \& Exercise 37:1338-1344.

Centers for Disease C, Prevention. 2006. Heat-related deaths--united states, 1999-2003. MMWR - Morbidity \& Mortality Weekly Report 55:796-798.

Charkoudian N, Stachenfeld N. 2016. Sex hormone effects on autonomic mechanisms of thermoregulation in humans. Autonomic Neuroscience 196:75-80.

Che Muhamed AM, Atkins K, Stannard SR, Mündel T, Thompson MW. 2016. The effects of a systematic increase in relative humidity on thermoregulatory and circulatory responses during prolonged running exercise in the heat. Temperature (Austin, Tex) 3:455-464.

Cramer MN, Jay O. 2016. Biophysical aspects of human thermoregulation during heat stress. Autonomic neuroscience : basic \& clinical 196:3-13.

Davis RE, Knappenberger PC, Michaels PJ, Novicoff WM. 2003. Changing heat-related mortality in the united states. Environmental Health Perspectives 111:1712-1718.

Ellis FP. 1972. Mortality from heat illness and heat-aggravated illness in the united states. Environmental Research 5:1-58.

Ellis FP, Prince HP, Lovatt G, Whittington RM. 1980. Mortality and morbidity in birmingham during the 1976 heatwave. QJM: An International Journal of Medicine 49:1-8.

Fortune MK, Mustard CA, Etches JJ, Chambers AG. 2013. Work-attributed illness arising from excess heat exposure in ontario, 2004-2010. Canadian Journal of Public Health Revue Canadienne de Sante Publique 104:e420-426.

Fowler DR, Mitchell CS, Brown A, Paulson J, Noller AC, Oscanyan K, et al. 2013. Heat-related deaths after an extreme heat event--four states, 2012, and united states, 1999-2009. MMWR Morb Mortal Wkly Rep 62:433-436.

Gagnon D, Kenny GP. 2012. Does sex have an independent effect on thermoeffector responses during exercise in the heat? The Journal of Physiology 590:5963-5973.

Gagnon D, Crandall CG, Kenny GP. 2013. Sex differences in postsynaptic sweating and cutaneous vasodilation. Journal of applied physiology (Bethesda, Md : 1985) 114:394-401

Gasparrini A, Guo Y, Sera F, Vicedo-Cabrera AM, Huber V, Tong S, et al. 2017. Projections of temperature-related excess mortality under climate change scenarios. The Lancet Planetary health 1:e360-e367.

Gu S, Huang C, Bai L, Chu C, Liu Q. 2016. Heat-related illness in china, summer of 2013. International Journal of Biometeorology 60:131137.

Gubernot DM, Anderson GB, Hunting KL. 2014. The epidemiology of occupational heat exposure in the united states: A review of the literature and assessment of research needs in a changing climate. Int J Biometeorol 58:1779-1788.

Gubernot DM, Anderson GB, Hunting KL. 2015. Characterizing occupational heat-related mortality in the united states, 2000-2010: An analysis using the census of fatal occupational injuries database. American Journal of Industrial Medicine 58:203-211.

Hallal PC, Andersen LB, Bull FC, Guthold R, Haskell W, Ekelund U. 2012. Global physical activity levels: Surveillance progress, pitfalls, and prospects. The Lancet 380:247-257.

Harduar Morano L, Bunn TL, Lackovic M, Lavender A, Dang GT, Chalmers JJ, et al. 2015. Occupational heat-related illness emergency department visits and inpatient hospitalizations in the southeast region, 2007-2011. American Journal of Industrial Medicine 58:1114-1125.

Harduar Morano L, Watkins S, Kintziger K. 2016. A comprehensive evaluation of the burden of heat-related illness and death within the florida population. Int J Environ Res Public Health 13.

Herbst J, Mason K, Byard RW, Gilbert JD, Charlwood C, Heath KJ, et al. 2014. Heat-related deaths in adelaide, south australia: Review of the literature and case findings - an australian perspective. Journal of Forensic \& Legal Medicine 22:73-78.

Hess JJ, Saha S, Luber G. 2014. Summertime acute heat illness in u.S. Emergency departments from 2006 through 2010: Analysis of a nationally representative sample.[erratum appears in environ health perspect. 2014 nov;122(11):A293]. Environmental Health Perspectives 122:1209-1215.

Houghton BL, Holowatz LA, Minson CT. 2005. Influence of progestin bioactivity on cutaneous vascular responses to passive heating. Med Sci Sports Exerc 37:45-51; discussion 52.

Huang W, Kan H, Kovats S. 2010. The impact of the 2003 heat wave on mortality in shanghai, china. Science of the Total Environment 408:2418-2420.

Huffman EA, Yard EE, Fields SK, Collins CL, Comstock RD. 2008. Epidemiology of rare injuries and conditions among united states high school athletes during the 2005-2006 and 2006-2007 school years. Journal of athletic training 43:624-630. 
Hughson RL, Green HJ, Houston ME, Thomson JA, MacLean DR, Sutton JR. 1980. Heat injuries in canadian mass participation runs. Canadian Medical Association Journal 122:1141-1144.

Johnson JM, Kellogg DL, Jr. 2010. Local thermal control of the human cutaneous circulation. Journal of applied physiology (Bethesda, Md : 1985) 109:1229-1238

Kenny GP, Jay O. 2013. Thermometry, calorimetry, and mean body temperature during heat stress. Compr Physiol 3:1689-1719.

Kenny GP, Sigal RJ, McGinn R. 2016. Body temperature regulation in diabetes. Temperature (Austin, Tex) 3:119-145.

Kenttamies A, Karkola K. 2008. Death in sauna. Journal of Forensic Sciences 53:724-729.

Khare S, Hajat S, Kovats S, Lefevre CE, de Bruin WB, Dessai S, et al. 2015. Heat protection behaviour in the uk: Results of an online survey after the 2013 heatwave. BMC public health 15:878.

Leon LR, Bouchama A. 2015. Heat stroke. Compr Physiol 5:611-647.

Li J, Xu X, Ding G, Zhao Y, Zhao R, Xue F, et al. 2016. A cross-sectional study of heat wave-related knowledge, attitude, and practice among the public in the licheng district of jinan city, china. International journal of environmental research and public health 13.

Lindqvist PG, Marsal K, Merlo J, Pirhonen JP. 2003. Thermal response to submaximal exercise before, during and after pregnancy: A longitudinal study. Journal of Maternal-Fetal \& Neonatal Medicine 13:152-156.

Liu T, Xu YJ, Zhang YH, Yan QH, Song XL, Xie HY, et al. 2013. Associations between risk perception, spontaneous adaptation behavior to heat waves and heatstroke in guangdong province, china. BMC public health 13:913.

Lundgren-Kownacki K, Hornyanszky ED, Chu TA, Olsson JA, Becker P. 2018. Challenges of using air conditioning in an increasingly hot climate. International Journal of Biometeorology 62:401-412.

Marsh SA, Jenkins DG. 2002. Physiological responses to the menstrual cycle: Implications for the development of heat illness in female athletes. Sports medicine (Auckland, NZ) 32:601-614.

Michelozzi P, de Donato F, Bisanti L, Russo A, Cadum E, DeMaria M, et al. 2005. The impact of the summer 2003 heat waves on mortality in four italian cities. Euro Surveillance: Bulletin Europeen sur les Maladies Transmissibles = European Communicable Disease Bulletin 10:161-165.

Mirabelli MC, Richardson DB. 2005. Heat-related fatalities in north carolina. American Journal of Public Health 95:635-637.

Miyake Y. 2012. [characteristics of non-exertional heat-related illness in japan]. Nippon Rinsho - Japanese Journal of Clinical Medicine 70:997-1004.

Miyake Y. 2013. [characteristics of elderly heat illness patients in japan--analysis from heatstroke study 2010]. Nihon rinsho Japanese journal of clinical medicine 71:1065-1073.

Na W, Jang JY, Lee KE, Kim H, Jun B, Kwon JW, et al. 2013. The effects of temperature on heat-related illness according to the characteristics of patients during the summer of 2012 in the republic of korea. Journal of Preventive Medicine \& Public Health / Yebang Uihakhoe Chi 46:19-27.

Nadel ER, Pandolf KB, Roberts MF, Stolwijk JA. 1974. Mechanisms of thermal acclimation to exercise and heat. J Appl Physiol 37:515520.

Nakai S, Itoh T, Morimoto T. 1999. Deaths from heat-stroke in japan: 1968-1994. International Journal of Biometeorology 43:124-127.

Nakai S. 2012. [the epidemiology of heat disorders]. Nippon Rinsho - Japanese Journal of Clinical Medicine 70:934-939.

Nakai S. 2015. [historical changes and recent trends in heat stroke]. Koshu Eisei 79:366-372.

Nashold RD, Jentzen JM, Peterson PL, Remington PL. 1996. Heat-related deaths during the summer of 1995, wisconsin. Clin Neuropharmacol 19:252-258.

Nelson NG, Collins CL, Comstock RD, McKenzie LB. 2011. Exertional heat-related injuries treated in emergency departments in the u.S., 1997-2006. American Journal of Preventive Medicine 40:54-60.

Nitschke M, Hansen A, Bi P, Pisaniello D, Newbury J, Kitson A, et al. 2013. Risk factors, health effects and behaviour in older people during extreme heat: A survey in south australia. International journal of environmental research and public health 10:6721-6733.

Notley SR, Park J, Tagami K, Ohnishi N, Taylor NAS. 2017. Variations in body morphology explain sex differences in thermoeffector function during compensable heat stress. Exp Physiol 102:545-562.

Pillai SK, Noe RS, Murphy MW, Vaidyanathan A, Young R, Kieszak S, et al. 2014. Heat illness: Predictors of hospital admissions among emergency department visits-georgia, 2002-2008. Journal of Community Health 39:90-98.

Piver WT, Ando M, Ye F, Portier CJ. 1999. Temperature and air pollution as risk factors for heat stroke in tokyo, july and august 1980 1995. Environmental Health Perspectives 107:911-916.

Rey G, Jougla E, Fouillet A, Pavillon G, Bessemoulin P, Frayssinet P, et al. 2007. The impact of major heat waves on all-cause and causespecific mortality in france from 1971 to 2003. Int Arch Occup Environ Health 80:615-626. Epub 2007 Feb 2014.

Sanchez CA, Thomas KE, Malilay J, Annest JL. 2010. Nonfatal natural and environmental injuries treated in emergency departments, united states, 2001-2004. Fam Community Health 33:3-10.

Shattuck G, Hilferty M. 1933. Causes of deaths from heat in massachusetts. New England Journal of Medicine 209:319-329.

Shen T, Howe HL, Alo C, Moolenaar RL. 1998. Toward a broader definition of heat-related death: Comparison of mortality estimates from medical examiners' classification with those from total death differentials during the july 1995 heat wave in chicago, illinois. The American journal of forensic medicine and pathology 19:113-118.

Sinclair WH, Crowe MJ, Spinks WL, Leicht AS. 2007. Pre-pubertal children and exercise in hot and humid environments: A brief review. Journal of Sports Science \& Medicine 6:385-392.

Stacey MJ, Parsons IT, Woods DR, Taylor PN, Ross D, J Brett S. 2015. Susceptibility to exertional heat illness and hospitalisation risk in uk military personnel. BMJ Open Sport \&amp; Exercise Medicine 1.

Stachenfeld NS, Silva C, Keefe DL. 2000. Estrogen modifies the temperature effects of progesterone. Journal of applied physiology (Bethesda, Md : 1985) 88:1643-1649.

Stroup DF, Berlin JA, Morton SC, Olkin I, Williamson GD, Rennie D, et al. 2000. Meta-analysis of observational studies in epidemiology: A proposal for reporting. Meta-analysis of observational studies in epidemiology (moose) group. Jama 283:2008-2012.

Tawatsupa B, Yiengprugsawan V, Kjellstrom T, Berecki-Gisolf J, Seubsman SA, Sleigh A. 2013. Association between heat stress and occupational injury among thai workers: Findings of the thai cohort study. Industrial Health 51:34-46.

Taylor AJ, McGwin G, Jr. 2000. Temperature-related deaths in alabama. Southern Medical Journal 93:787-792.

Toloo GS, Yu W, Aitken P, FitzGerald G, Tong S. 2014. The impact of heatwaves on emergency department visits in brisbane, australia: A time series study. Crit Care 18:R69. doi: 10.1186/cc13826.

Toulemon L, Barbieri M. 2008. The mortality impact of the august 2003 heat wave in france: Investigating the 'harvesting' effect and other long-term consequences. Population Studies 62:39-53.

Tran KV, Azhar GS, Nair R, Knowlton K, Jaiswal A, Sheffield P, et al. 2013. A cross-sectional, randomized cluster sample survey of household vulnerability to extreme heat among slum dwellers in ahmedabad, india. International Journal of Environmental Research \& Public Health [Electronic Resource] 10:2515-2543. 
Vaha-Eskeli K, Erkkola R, Seppanen A. 1991. Is the heat dissipating ability enhanced during pregnancy? European Journal of Obstetrics, Gynecology, \& Reproductive Biology 39:169-174.

Viechtbauer W. 2007. Hypothesis tests for population heterogeneity in meta-analysis. British Journal of Mathematical and Statistical Psychology:29-60.

Vogel JA, Friedl KE. 1992. Body fat assessment in women. Special considerations. Sports medicine (Auckland, NZ) 13:245-269.

Wallace RF, Kriebel D, Punnett L, Wegman DH, Wenger CB, Gardner JW, et al. 2006. Risk factors for recruit exertional heat illness by gender and training period. Aviation Space \& Environmental Medicine 77:415-421.

Wheeler K, Lane K, Walters S, Matte T. 2013. Heat illness and deaths--new york city, 2000-2011. MMWR Morb Mortal Wkly Rep 62:617621.

Wong BJ, Hollowed CG. 2017. Current concepts of active vasodilation in human skin. Temperature (Austin) 4:41-59.

Yamamoto T, Todani M, Oda Y, Kaneko T, Kaneda K, Fujita M, et al. 2015. Predictive factors for hospitalization of patients with heat

illness in yamaguchi, japan. International Journal of Environmental Research \& Public Health [Electronic Resource] 12:11770-11780.

\section{Figure captions}

Figure 1: Search, selection and exclusion process

Figure 2:. Comparison of HI by sex and age where reported. Black bars represent male HI cases, grey bars female. * Synthesis of three publications plus additional data kindly provided by lead author Prof S. Nakai.; all other data presented by kind permission of the authors. Left panel: studies grouped where age was reported in decades from age 20. Top: comparison of HI-related ED presentations, Georgia, USA (2002-2008). ${ }^{29}$ Second from top: deaths caused by HS in Japan, 1968-2015. ${ }^{415} 16$ Second from bottom: HI presentations to ED, Japan, 2011. ${ }^{32}$ Bottom: deaths due to HI in Alabama, USA, 1987-1998 (rate per 100,000).(Miyake 2012; Nakai et al. 1999; Nakai 2012, 2015; Pillai et al. 2014; Taylor and McGwin 2000) Right panel: HI comparison by sex grouped where age reported in decades from 15. Top: workrelated presentations to ED for HI in Canada, 2004-2010 (rate [95\% CI] per 1,000,000 fulltime employment months) (Fortune et al. 2013), bottom: deaths caused by HI, USA (19992003) (Centers for Disease and Prevention 2006) [redrawn with kind permission and assistance from Dr Cathy Lansdowne and Dr George Luber, MMWR]. HI, heat illness; ED emergency department, CI confidence interval; FTE, full-time employment, MMWR Morbidity and Mortality Weekly Report.

Figure 3: Meta-analysis: incident rate ratio for HI outcomes in men compared with women. In some cases, e.g. Gu et al., AFHS, Hess et al and Mirabelli et al., CIs are wide due to very small numbers of cases reported relative to population size. 3A: Meta-analysis: incident rate ratio for four heat-related illness outcomes in men compared with women. 3B: Meta-analysis of studies reporting occupational and non-occupational HI. Top panel: occupational HI only. Bottom panel: non-occupational HI only. 
ED: emergency department, HRI: heat-related illness, CI: confidence interval, n/N/year: incident cases per number population per year, RE: relative effect, AFHS: Armed Forces Health Surveillance Committee. 